\title{
Noninvasive diagnosis of chemotherapy induced liver injury by LiMAx test - two case reports and a review of the literature
}

\author{
Jan Bednarsch, Maximilian Jara, Johan Friso Lock, Maciej Malinowski, Johann Pratschke and Martin Stockmann*
}

\begin{abstract}
Background: Chemotherapy-induced liver injury is a well-known phenomenon after neoadjuvant therapy of liver metastasis and contributes to postoperative morbidity and mortality. Still there is no suitable test available to reliably determine functional impairment and hepatic regeneration after chemotherapy.

Case presentation: We report two cases of caucasian patients who underwent repeated liver function assessments using LiMAx (maximum liver function capacity), Indocyanine plasma disappearance rate and biochemical liver function parameters in the course of adjuvant oxaliplatin-based chemotherapy.

Both patients yielded a decrease from their initial liver function determined by LiMAx. Liver regeneration assessed functional recovery within 4 weeks in case of mild functional impairment after cessation of chemotherapy or within 8 weeks in case of major functional deterioration. Indocyanine plasma disappearance rate and biochemical parameters remained stable or without a clear trend in case of minor functional impairment. This is the first report using a dynamic liver function test to evaluate the impact and recovery from chemotherapy associated liver injury.

Conclusions: The LiMAx test might be a sensitive tool to diagnose mild functional impairment after chemotherapy when standard liver function tests have remained within normal ranges and might be capable to assess the course of regeneration after chemotherapy. This could be useful to optimize individual chemotherapy-free interval before liver surgery can be carried out safely.
\end{abstract}

Keywords: LiMAx, ICG-PDR, Liver function, Chemotherapy induced liver injury, Methacetin

\section{Background}

Chemotherapy-induced liver injury (CALI) after receiving potent chemotherapy is a considerable problem in patients undergoing partial liver resection since increased perioperative mortality and morbidity have been reported [1-3]. However patients presenting with multiple liver metastasis frequently require preoperative chemotherapy to downstage their initially unresectable disease [4-6]. In this context oxaliplatin-based chemotherapeutic regimes - e.g. FOLFOX or FOLFOXIRI - showed promising ability to downstage spread and size but also increased perioperative morbidity $[3,7,8]$.

Whereas previous studies were based on the clinical course and histology of resected liver parenchyma after

\footnotetext{
* Correspondence: martin.stockmann@charite.de

Department of General, Visceral and Transplantation Surgery, Charité University Hospital, Augustenburger Platz 1, 13353 Berlin, Germany
}

surgery, less is known about the impact on actual liver function and the course of regeneration after cessation of chemotherapy $[9,10]$.

Clinical biochemistry usually fail to diagnose reduced liver function after neoadjuvant therapy as standard parameters remain within normal ranges [11]. The frequently applied indocyanine green plasma disappearance rate test (ICG-PDR) also showed conflicting results in predicting operative outcome after chemotherapy [7,12-15].

Concerning the chemotherapy-free interval from cessation of chemotherapy to a safe partial liver resection only statistical figures are known in the literature and suggest an interval of six to eight weeks [16]. There is evidence that vulnerability to especially oxaliplatin-based liver injury might be different between patients. Thus an individual time frame between chemotherapy and surgery 
based on individual liver function and regeneration might be superior to a fixed interval $[17,18]$.

\section{Case presentation}

Here we report two cases of patients that both received adjuvant oxaliplatin-based chemotherapy as a consequence of colorectal surgery due to adenocarcinoma. All patients underwent assessment of liver function using common biochemical liver tests, ICG-PDR and LiMAx (maximum liver function capacity) test before, directly after withdrawal as well as 4 and 8 weeks after cessation of chemotherapy. Both patients did not have additional regular drug intake during the study period and did not suffer from any marked comorbidities known to impair liver function.

LiMAx (maximum liver function capacity) reflects the actual enzymatic liver function capacity. The test is based on a bodyweight-adjusted intravenous ${ }^{13} \mathrm{C}$-labeled methacetin bolus injection and continuous measurement of ${ }^{13} \mathrm{CO}_{2} /{ }^{12} \mathrm{CO}_{2}$ concentration ratio using a special device (FLIP, Humedics GmbH, Berlin, Germany) as previously described by Stockmann and colleagues [19]. The LiMAx test (Figure 1) was developed and recently introduced into clinical routine in our department showing superior accuracy in diagnosing postoperative liver failure and early graft dysfunction after liver transplantation [19-21]. LiMAx values $>315 \mu \mathrm{g} / \mathrm{kg} / \mathrm{h}$ are considered normal.

Indocyanine green plasma disappearance rate (ICGPDR) evaluates hepatic clearance and is suggested to provide additional information on liver function. The

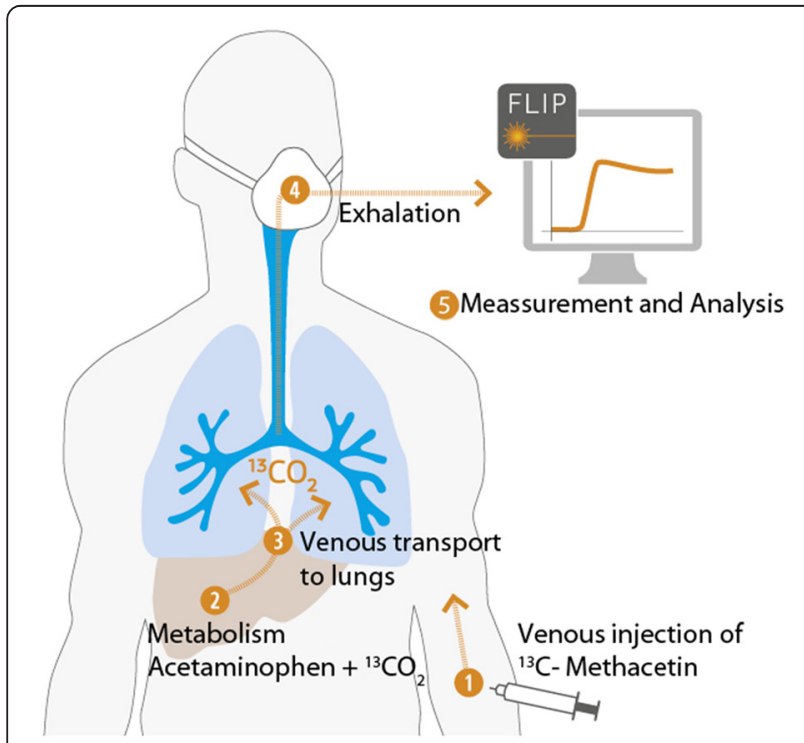

Figure 1 Concept of the LiMAx test. The figure is property of Humedics GmbH (Berlin, Germany), the company marketing the LiMAx test. The authors have the unrestricted permission to use the figure for this publication. test is based on bodyweight-adjusted intravenous injection of ICG followed by pulse spectrophotometry to assess hepatic excretion via a special device (Dye Densitogram Analyzer DDG2001, Nihon Khoden, Tokyo, Japan). ICGPDR is considered to be normal over $18 \% /$ min $[22,23]$.

\section{Case 1}

Case 1 reports a 56-year-old male caucasian patient that received 8 cycles of XELOX chemotherapy substituting 5-FU for the oral drug Xeloda. The patient started XELOX chemotherapy with a LiMAx value of $463 \mu \mathrm{g} /$ $\mathrm{kg} / \mathrm{h}$ and showed a decrease of functional liver capacity by $56 \%$ to $204 \mu \mathrm{g} / \mathrm{kg} / \mathrm{h}$ after withdrawal of chemotherapy. ICG-PDR also declined from physiological 19.3\%/ min prior to chemotherapy to $16.6 \% /$ min (Figure 2). In terms of regeneration LiMAx indicates a continuous course regaining liver function after a chemotherapyfree interval of 8 weeks. In contrast ICG-PDR persisted to decrease until 4 weeks after cessation of chemotherapy. However it also restored its value by week 8 . Biochemistry showed a peak of serum bilirubin directly after chemotherapy and a temporary decrease in butyrylcholinesterase (BChE) until 8 weeks after withdrawal of XELOX (Table 1).

\section{Case 2}

Case 2 is a 68 -year-old female caucasian patient that underwent 12 cycles of FOLFOX4 chemotherapy. This patient started chemotherapy with a LiMAx value of $488 \mu \mathrm{g} / \mathrm{kg} / \mathrm{h}$ and showed a decrease of functional liver capacity by $24 \%$ to $373 \mu \mathrm{g} / \mathrm{kg} / \mathrm{h}$ after withdrawal of chemotherapy. Four weeks after cessation of chemotherapy initial liver function was regained and remained constant during follow-up. ICG-PDR showed no clear trend

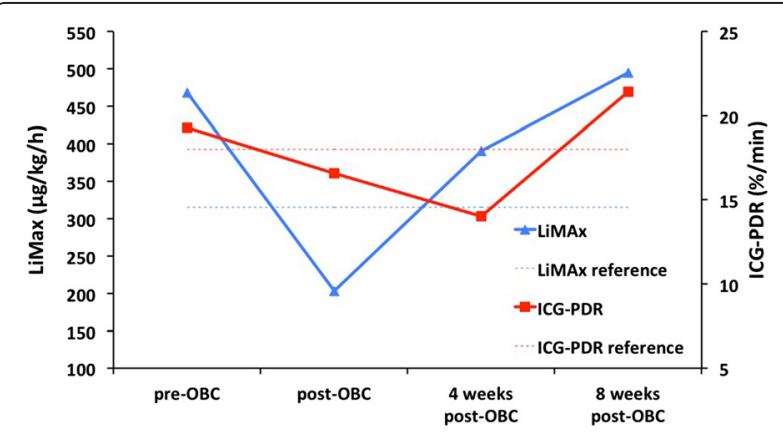

Figure 2 Dynamic liver function assessment by LiMAx and Indocyanine green plasma disappearance rate in Case 1.

Patients' liver function capacity measured by LiMAx was reduced by $56 \%$ after chemotherapy and ICG-PDR by $14 \%$. Despite showing a different course of regeneration, both dynamic liver function tests indicate functional recovery within 8 weeks after cessation of chemotherapy. pre-Chemo - prior to chemotherapy, post-Chemo after cessation of chemotherapy, 4 weeks -4 weeks after cessation of chemotherapy, 8 weeks -8 weeks after cessation of chemotherapy. 
Table 1 Liver function assessment of case 1

\begin{tabular}{|c|c|c|c|c|c|}
\hline Laboratory parameters & Reference range & pre-Chemo & post-Chemo & 4 weeks & 8 weeks \\
\hline LiMAx ( $\mu \mathrm{g} / \mathrm{kg} / \mathrm{h})$ & $>315$ & 468 & 203 & 390 & 495 \\
\hline ICG-PDR (\%/min) & $>18$ & 19.3 & 16.6 & 14 & 21.4 \\
\hline $\mathrm{ALT}(\mathrm{U} / \mathrm{L})$ & $10-50$ & 41.00 & 33.00 & 34.00 & 41.00 \\
\hline Bilirubin (mg/dL) & $<1$ & 0.6 & 2.15 & 1.08 & 1.03 \\
\hline INR & $0,7-1,3$ & 0.97 & 1.43 & 1.04 & 1.04 \\
\hline BChE (kU/L) & $>5.3$ & 6.47 & 3.88 & 4.97 & 7.11 \\
\hline
\end{tabular}

pre-Chemo - prior to chemotherapy, post-Chemo - after cessation of chemotherapy, 4 weeks - 4 weeks after cessation of Chemotherapy, 8 weeks - 8 weeks after cessation of chemotherapy, LiMAx - Maximum liver function capacity, ICG-PDR, Indocyanine green plasma disappearance rate, ALT - Alanine transaminase, INR international normalized ratio, $\mathrm{BChE}$ - Butyrylcholinesterase.

and remained throughout all visits within the reference range (Figure 3). Biochemical liver parameters were also within the reference ranges on each visit (Table 2).

\section{Discussion}

To our knowledge this is the first report using quantitative liver function tests to assess deterioration and regeneration of liver function duo to chemotherapy in controlled prospective design with multiple testing. The reported patients may be of interest as on patient showed changes in common blood liver function tests indicating marked impairment of liver function whereas the other patient had no significant changes in standard liver function tests.

In accordance with this observation both dynamic liver function tests showed a major decrease in liver function reaching pathological values in case 1 in comparisons to case 2 where only a mild impairment of liver function could be measured with the LiMAx test. LiMAx indicates a defined course of regeneration in both cases but a delay in case 1. ICG-PDR seems to be a good indicator for regeneration in the case of major

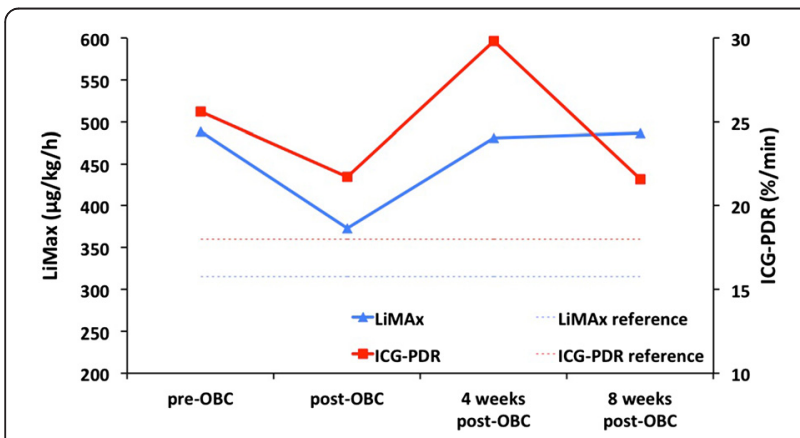

Figure 3 Dynamic liver function assessment by LiMAx and Indocyanine green plasma disappearance rate in Case 2. Patients' liver function capacity measured by LiMAx was reduced by 24\% after chemotherapy. Four weeks after cessation of FOLFOX the patient had already regained former liver function. ICG PDR showed no clear trend. pre-Chemo - prior to chemotherapy, post-Chemo after cessation of chemotherapy, 4 weeks - 4 weeks after cessation of chemotherapy, 8 weeks -8 weeks after cessation of chemotherapy. impairment of liver function (case 1), however ICG-PDR results in case 2 are inconclusive. This might be explained by general limitations of this testing procedure. ICG-PDR is strongly dependent on blood flow to the liver and the absence of cholestasis [24-26]. Since damage to liver sinusoids accompanied with sinusoidal obstruction is the basic pathological mechanism in oxaliplatin-based liver injury it is debatable whether ICG-PDR is a good indicator for liver function in this explicit clinical situation [9,27]. The usefulness of ICG-PDR after chemotherapy has already been questioned by Wakiya et al. [15].

Both LiMAx and ICG-PDR have shown superior prognostic relevance for perioperative mortality and morbidity in patients undergoing partial liver resection compared to standard liver function tests $[19,20,28,29]$. Clinical decision trees exist for both testing procedures allowing accurate risk stratification and prediction of postoperative liver failure. The presented cases support the hypothesis that regeneration of liver function has a defined course, which is accessible by means of dynamic liver functions tests which could be used to evaluate the optimal chemotherapy-free interval prior to partial liver resection using adequate decision algorithms [20,28]. In particular enzymatic based LiMAx test may also assess mild impairment of liver function - which can contribute to poorer postoperative outcome - providing additional information compared to standard blood borne liver function tests and ICG-PDR.

Certainly we present cases in patients without liver metastases and without indication for liver surgery. However our workgroup has already shown that the sole presence of liver metastasis which is usually advanced in patients that undergo neoadjuvant treatment can also impair liver function making it impossible to discriminate between reduction of liver function by chemotherapy or multiple metastasis in a proof of principle report [30].

\section{Conclusions}

This is the first report using a dynamic liver function test in a controlled prospective setting to assess 
Table 2 Liver function assessment of case 2

\begin{tabular}{|c|c|c|c|c|c|}
\hline Laboratory parameters & Reference range & pre-Chemo & post-Chemo & 4 weeks & 8 weeks \\
\hline LiMAx ( $\mu \mathrm{g} / \mathrm{kg} / \mathrm{h})$ & $>315$ & 488 & 373 & 481 & 487 \\
\hline ICG-PDR (\%/min) & $>18$ & 25.6 & 21.7 & 29.8 & 21.6 \\
\hline ALT (U/L) & $7-35$ & 13.00 & 26.00 & 17.00 & 21.00 \\
\hline Bilirubin (mg/dL) & $<1$ & 0.27 & 0.62 & 0.56 & 0.39 \\
\hline INR & $0,7-1,3$ & 0.95 & 1.12 & 0.95 & 1.02 \\
\hline $\mathrm{BChE}(\mathrm{kU} / \mathrm{L})$ & $>5.3$ & 6.32 & 5.64 & 6.10 & 6.69 \\
\hline
\end{tabular}

pre-Chemo - prior to chemotherapy, post-Chemo - after cessation of chemotherapy, 4 weeks - 4 weeks after cessation of Chemotherapy, 8 weeks - 8 weeks after cessation of chemotherapy, LiMAx - Maximum liver function capacity, ICG-PDR, Indocyanine green plasma disappearance rate, ALT - Alanine transaminase, INR international normalized ratio, $\mathrm{BChE}$ - Butyrylcholinesterase.

chemotherapy induced liver injury. It suggests an impairment of liver function, which might not be recognised by standard liver function tests and a defined course of regeneration after chemotherapy measurable with dynamic liver function tests. This might help to optimize the chemotherapy-free interval prior to liver surgery and therefore needs to be addressed in a larger cohort.

\section{Consent}

Written informed consent was obtained from both patients for publication of this Case Report and any accompanying images. A copy of the written consent is available for review by the Editor-in-Chief of this journal.

\section{Abbreviations}

CALI: Chemotherapy associated liver injury; ICG: Indocyanine green; PDR: Plasma disappearance rate; ALT: Alanine transaminase; INR: International normalized ratio; BChE: Butyrylcholinesterase.

\section{Competing interests}

Martin Stockmann MD PhD is the inventor of the LiMAx-Test and has capital interest in its sales company Humedics $\mathrm{GmbH}$. All other authors declare that they have no competing interests.

\section{Authors' contributions}

All authors reviewed and accepted the manuscript. JB participated in conception and organization of the case report, carried out the liver function assessments and wrote the manuscript. MJ contributed conception and organized the case report and contributed to draft the manuscript. JFL, MM, JP and MS participated in conception, organized the case report and critical revised the manuscript. All authors read and approved the final manuscript.

Received: 16 March 2014 Accepted: 12 March 2015

Published online: 26 March 2015

\section{References}

1. Vauthey JN, Pawlik TM, Ribero D, Wu TT, Zorzi D, Hoff PM, et al. Chemotherapy regimen predicts steatohepatitis and an increase in 90-day mortality after surgery for hepatic colorectal metastases. J Clin Oncol. 2006:24:2065-72.

2. Karoui M, Penna C, Amin-Hashem M, Mitry E, Benoist S, Franc B, et al. Influence of preoperative chemotherapy on the risk of major hepatectomy for colorectal liver metastases. Ann Surg. 2006;243:1-7.

3. Nordlinger B, Sorbye H, Glimelius B, Poston GJ, Schlag PM, Rougier P, et al. Perioperative chemotherapy with FOLFOX4 and surgery versus surgery alone for resectable liver metastases from colorectal cancer (EORTC Intergroup trial 40983): a randomised controlled trial. Lancet. 2008;371:1007-16

4. Folprecht G, Gruenberger T, Bechstein WO, Raab HR, Lordick F, Hartmann JT, et al. Tumour response and secondary resectability of colorectal liver metastases following neoadjuvant chemotherapy with cetuximab: the CELIM randomised phase 2 trial. Lancet Oncol. 2010;11:38-47.

5. Garufi C, Torsello A, Tumolo S, Ettorre GM, Zeuli M, Campanella C, et al. Cetuximab plus chronomodulated irinotecan, 5-fluorouracil, leucovorin and oxaliplatin as neoadjuvant chemotherapy in colorectal liver metastases: POCHER trial. Br J Cancer. 2010;103:1542-7.

6. Saltz LB, Clarke S, Diaz-Rubio E, Scheithauer W, Figer A, Wong R, et al. Bevacizumab in combination with oxaliplatin-based chemotherapy as first-line therapy in metastatic colorectal cancer: a randomized phase III study. J Clin Oncol. 2008;26:2013-9.

7. Nakano H, Oussoultzoglou E, Rosso E, Casnedi S, Chenard-Neu MP, Dufour $P$, et al. Sinusoidal injury increases morbidity after major hepatectomy in patients with colorectal liver metastases receiving preoperative chemotherapy. Ann Surg. 2008;247:118-24.

8. Aloia T, Sebagh M, Plasse M, Karam V, Levi F, Giacchetti S, et al. Liver histology and surgical outcomes after preoperative chemotherapy with fluorouracil plus oxaliplatin in colorectal cancer liver metastases. J Clin Oncol. 2006:24:4983-90.

9. Rubbia-Brandt L, Audard V, Sartoretti P, Roth AD, Brezault C, Le Charpentier $M$, et al. Severe hepatic sinusoidal obstruction associated with oxaliplatin-based chemotherapy in patients with metastatic colorectal cancer. Ann Oncol. 2004;15:460-6.

10. Rubbia-Brandt L, Lauwers GY, Wang H, Majno PE, Tanabe $K$, Zhu AX, et al. Sinusoidal obstruction syndrome and nodular regenerative hyperplasia are frequent oxaliplatin-associated liver lesions and partially prevented by bevacizumab in patients with hepatic colorectal metastasis. Histopathology. 2010;56:430-9.

11. Cleary JM, Tanabe KT, Lauwers GY, Zhu AX. Hepatic toxicities associated with the use of preoperative systemic therapy in patients with metastatic colorectal adenocarcinoma to the liver. Oncologist. 2009;14:1095-105.

12. Krieger PM, Tamandl D, Herberger B, Faybik P, Fleischmann E, Maresch J, et al. Evaluation of chemotherapy-associated liver injury in patients with colorectal cancer liver metastases using indocyanine green clearance testing. Ann Surg Oncol. 2011;18:1644-50.

13. Takamoto T, Hashimoto T, Sano K, Maruyama Y, Inoue K, Ogata S, et al. Recovery of liver function after the cessation of preoperative chemotherapy for colorectal liver metastasis. Ann Surg Oncol. 2010;17:2747-55.

14. Narita M, Oussoultzoglou E, Chenard MP, Fuchshuber P, Rather M, Rosso E, et al. Liver injury due to chemotherapy-induced sinusoidal obstruction syndrome is associated with sinusoidal capillarization. Ann Surg Oncol. 2012;19:2230-7

15. Wakiya T, Kudo D, Toyoki Y, Ishido K, Kimura N, Narumi S, et al. Evaluation of the usefulness of the indocyanine green clearance test for chemotherapyassociated liver injury in patients with colorectal cancer liver metastasis. Annals Surg Oncol. 2014;21:167-72

16. Welsh FK, Tilney HS, Tekkis PP, John TG, Rees M. Safe liver resection following chemotherapy for colorectal metastases is a matter of timing. Br J Cancer. 2007;96:1037-42.

17. Robinson SM, Mann J, Vasilaki A, Mathers J, Burt AD, Oakley F, et al. Pathogenesis of FOLFOX induced sinusoidal obstruction syndrome in a murine chemotherapy model. J Hepatol. 2013;59:318-26.

18. Robinson SM, Mann J, Manas DM, Mann DA, White SA. An experimental study to identify the potential role of pharmacogenomics in determining the occurrence of oxaliplatin-induced liver injury. HPB. 2013;15:581-7. 
19. Stockmann M, Lock JF, Riecke B, Heyne K, Martus P. Fricke M, et al. Prediction of postoperative outcome after hepatectomy with a new bedside test for maximal liver function capacity. Ann Surg. 2009;250:119-25.

20. Stockmann M, Lock JF, Malinowski M, Niehues SM, Seehofer D, Neuhaus P. The LiMAx test: a new liver function test for predicting postoperative outcome in liver surgery. HPB. 2010;12:139-46.

21. Stockmann M, Lock JF, Malinowski M, Seehofer D, Puhl G, Pratschke J, et al. How to define initial poor graft function after liver transplantation? - a new functional definition by the LiMAx test. Transplant Int. 2010;23:1023-32.

22. Leevy CM, Smith F, Longueville J, Paumgartner G, Howard MM. Indocyanine green clearance as a test for hepatic function. Evaluation by dichromatic ear densitometry. JAMA. 1967;200:236-40.

23. Mizushima Y, Tohira H, Mizobata Y, Matsuoka T, Yokota J. Assessment of effective hepatic blood flow in critically ill patients by noninvasive pulse dye-densitometry. Surg Today. 2003:33:101-5.

24. Stehr A, Ploner F, Traeger $\mathrm{K}$, Theisen M, Zuelke C, Radermacher $\mathrm{P}$, et al. Plasma disappearance of indocyanine green: a marker for excretory liver function? Intensive Care Med. 2005;31:1719-22.

25. Bruegger L, Studer P, Schmid SW, Pestel G, Reichen J, Seiler C, et al. Indocyanine green plasma disappearance rate during the anhepatic phase of orthotopic liver transplantation. J Gastrointest Surg. 2008;12:67-72.

26. Stockmann M, Malinowski M, Lock JF, Seehofer D, Neuhaus P. Factors influencing the indocyanine green (ICG) test: additional impact of acute cholestasis. Hepato-Gastroenterology. 2009:56:734-8.

27. Schiffer E, Frossard JL, Rubbia-Brandt L, Mentha G, Pastor CM. Hepatic regeneration is decreased in a rat model of sinusoidal obstruction syndrome. J Surg Oncol. 2009;99:439-46.

28. Imamura H, Sano K, Sugawara Y, Kokudo N, Makuuchi M. Assessment of hepatic reserve for indication of hepatic resection: decision tree incorporating indocyanine green test. J Hepato-Biliary-Pancreat Surg. 2005;12:16-22

29. Imamura H, Seyama $Y$, Kokudo N, Maema A, Sugawara $Y$, Sano $K$, et al. One thousand fifty-six hepatectomies without mortality in 8 years. Arch Surg. 2003;138:1198-206. discussion 1206

30. Lock JF, Westphal T, Malinowski M, Schulz A, Neuhaus P, Stockmann M. Assessing individual hepatic impairment after chemotherapy prior resection of colorectal metastases. Eur J Surg Oncol. 2012;38:796.

\section{Submit your next manuscript to BioMed Central and take full advantage of:}

- Convenient online submission

- Thorough peer review

- No space constraints or color figure charges

- Immediate publication on acceptance

- Inclusion in PubMed, CAS, Scopus and Google Scholar

- Research which is freely available for redistribution 